\section{PRAXIOLOGIA MOTRIZ E A ORGANIZAÇÃO DO TRABALHO PEDAGÓGICO E DA DIDÁTICA NA EDUCAÇÃO FÍSICA: ENTREVISTA COM PIERRE PARLEBAS, PROFESSOR DA UNIVERSIDADE PARIS DESCARTES (PARIS V - SORBONNE CITÉ)}

\author{
MOTOR PRAXEOLOGY AND ORGANIZATION OF PEDAGOGICAL \\ WORK AND DIDACTICS IN PHYSICAL EDUCATION: AN INTERVIEW \\ WITH PARIS DESCARTES UNIVERSITY (PARIS V - SORBONNE CITÉ) \\ PROFESSOR PIERRE PARLEBAS
}

PRAXIOLOGÍA MOTRIZ Y LA ORGANIZACIÓN DEL TRABAJO
PEDAGÓGICO Y LA DIDÁCTICA EN LA EDUCACIÓN FISICA:
ENTREVISTA CON PIERRE PARLEBAS, PROFESOR DE LA
UNIVERSIDAD PARÍS DESCARTES (PARIS V - SORBONNE CITÉ)

\author{
João Francisco Magno Ribas*, Flávia Franco**
}

Palavras chave: Ensino.

Educação Física. Conhecimento. Entrevista.

Keywords: Teaching. Physical Education. Knowledge. Interview.

Palabras clave: Enseñanza. Educación física. Conocimiento. Entrevista.
Resumo: Este texto é o resultado de uma entrevista realizada, em junho de 2015, com o Dr. Pierre Parlebas, idealizador da Praxiologia Motriz. A entrevista se estruturou em três momentos e teve o objetivo de estabelecer as relações entre o conhecimento praxiológico e a organização do trabalho pedagógico e da didática na Educaçao Física. Iniciou-se questionando a respeito das características epistemológicas do conhecimento praxiológico. Em seguida, verificou-se como o professor situa o conhecimento praxiológico no campo da Educação Física. Finalizou-se a entrevista solicitando que o autor apresentasse as relações entre Praxiologia Motriz, Trabalho Pedagógico e Didática.

Abstract: This article is the result of a June 2015 interview with Motor Praxeology creator Dr. Pierre Parlebas. Its goal was to establish the relationship between praxiological knowledge and organization of pedagogical work and didactics in Physical Education. The interview was divided into three parts. Firstly, we asked Dr. Parlebas about the epistemological characteristics of praxiological knowledge. Secondly, we focused on how he sees the place of that knowledge within the field of Physical Education. Finally, we asked the author to explain the connections between Motor Praxeology, Pedagogical practice and Didactics.

Resumen: Este texto es el resultado de una entrevista realizada, en junio de 2015, con el Dr. Pierre Parlebas, creador de la praxiología motriz. La entrevista se estructuró en tres momentos y tuvo como objetivo establecer las relaciones entre el conocimiento praxiológico y la organización del trabajo pedagógico y la didáctica en la Educación Física. Lo primero fue cuestionar acerca de las características epistemológicas del conocimiento praxiológico. A continuación, se intentó saber cómo el profesor sitúa el conocimiento praxiológico en el campo de la Educación Física. La entrevista finaliza solicitando que el autor presente las relaciones entre praxiología motriz, trabajo pedagógico y didáctica.
* Universidade Federal de Santa Maria (UFSM). Santa Maria, RS, Brasil.

E-mail

ribasjfm@hotmail.com

** Universidad del País Vasco, País Basco, Espanha.

E-mail:

flacfranco@hotmail.com

Recebido em: 16-07-2019 Aprovado em: 22-11-2019 Publicado em: 12-02-2020 (c) (i) (8) Licence 


\section{INTRODUÇÃO}

Em 2012, o professor Jorge Ricardo Saraví da Universidade de La Plata, Argentina, publicou uma entrevista com o professor Pierre Parlebas, professor da Universidade de Sorbonne, França, autor da teoria da Ação Motriz. Na oportunidade, Saraví (2012) desafiou o professor Parlebas a discutir o presente, o passado e o futuro desse conhecimento científico. O pesquisador apresentou as principais justificativas teóricas para esta área indicando as dificuldades iniciais da sua implementação, culminando com debates relevantes e atuais que têm sido importantes para a área da Educação Física, e defendeu a tese de que a Praxiologia Motriz podería ser o eixo central da Educação Física no futuro.

Em 2015, Pierre Parlebas esteve duas vezes no Brasil, em maio para participar do III Seminário Latinoamericano de Praxiologia Motriz em Santa Maria, RS, e em setembro na cidade de Campinas, SP, para receber o título de Professor Honoris Causa pela UNICAMP. No mês de junho Parlebas gentilmente concedeu uma entrevista com o objetivo de tratar o ponto de vista da Praxiologia Motriz em relação com um tema que consideramos bastante relevante atualmente para a Educação Física Brasileira: a organização do trabalho pedagógico e da didática. Esta preocupação teve como motivação principalmente dois trabalhos que tratam este tema, no caso, Caparroz; Bracht (2007) e Carlan; Domingues; Kunz (2009).

No trabalho de Caparroz e Bracht (2007, p. 21) encontramos a discussão pautada em duas questões: 1) "Estaria a produção acadêmica e, em função disso, também os cursos de formação de professores de educação física, hipertrofiando as discussões pedagógicas e atrofiando as discussões da didática da educação física escolar? 2) Qual o espaço e o lugar da didática na educação física"? Os autores destacam a polarização da discussão entre teoria e prática, com a tendência do momento atual para as bases teóricas, representadas pelas teorias pedagógicas, onde os princípios didáticos e pedagógicos se sobrepõem aos métodos e técnicas de ensino das manifestações da cultura corporal. Apontam para a retomada dessa articulação entre teoria e prática, princípios teóricos/didáticos e os métodos e técnicas de ensino.

Carlan, Domingues e Kunz (2009) analizaram o tratamento e o papel que a didática vem assumindo nas concepções críticas da Educação Física. Os autores concluíram nesse artigo que essas concepções apresentam diferenças significativas e que a Didática se constitui fundante para as concepções críticas.

Entretanto, em ambos os estudos, observou-se a ausência de um olhar que pudesse instrumentalizar o professor de Educação Física desde a perspectiva da própria manifestação, de sua lógica de funcionamento, como acontece, por exemplo, na teoria musical ou na gramática (PARLEBAS, 2001). Que características têm o futebol? Quais traços dessas modalidades encontram-se no basquetebol? Podemos transferir conhecimentos ou conceitos? Que critérios com ampla sustentação teórica já foram elaborados para classificar e compreender uma manifestação de jogo ou esporte que possibilitem buscar métodos e técnicas de ensino que atendam às características da manifestação? 


\section{METODOLOGIA}

Por isso, buscou-se identificar nesta entrevista com o professor Pierre Parlebas, que com árduo e criterioso esforço científico, elaborou uma inovadora teoria dos jogos e esportes que há mais de 40 anos vem mostrando as suas implicações didáticas e pedagógicas. Ou seja, nesta entrevista, diferente da entrevista realizada pelo professor Jorge Ricardo Saraví em 2012 que buscou analisar os alcances e suas dificuldades para consolidar-se como conhecimento científico, colocou-se o foco na perspectiva praxiológica, da lógica interna, da lógica de funcionamento das manifestações de jogos e esportes e suas relações com o trabalho pedagógico e a didática da Educação Física. Assim, levantou-se a seguinte questão: Que contribuições a Praxiologia Motriz traz à organização do trabalho pedagógico e da didática da Educação Física? Para chegarmos aos aspectos didáticos foi necessário solicitar que o autor partisse dos aspectos epistemológicos, que sustentam essa teoria, assim como, a situasse na pedagogia das manifestações da cultura corporal.

Com tanto tempo de diálogo transcrito, que demandou muita paciência e generosidade do autor, tivemos que restringir esta apresentação às questões centrais propostas inicialmente na entrevista. Assim, na sequência, apresenta-se o resultado da importante contribuição de Parlebas à Educação Física, considerandose três momentos. Iniciamos questionando-Ihe a respeito das características epistemológicas do conhecimento praxiológico. Em seguida, verificando como o autor situa o conhecimento praxiológico no campo da Educação Física. Finalizando a entrevista com Parlebas esclarecendo as relações entre Praxiologia Motriz e Trabalho Pedagógico.

\section{ENTREVISTA}

Entrevistadores (E) - Quais são as características epistemológicas do conhecimento praxiológico, da concepção teórica predominante e onde podemos situá-lo no campo de conhecimento da educação física?

Pierre Parlebas (P)-Bem, epistemologiaé uma reflexão sobre o conhecimento. O problema é: há, em relação à educação física, uma reflexão sólida, científica, que possa ser conduzida? Até agora, em educação física, havia muitas coisas fechadas, dentre as quais algumas são muito interessantes, mas sempre no modo de afirmação livre, no modo do encantamento, fala-se: "a educação física desenvolve tais e quais coisas", mas não se oferece nenhuma prova. O problema é que, se se quer ser parte de um quadro epistemológico correto, é preciso definir um objeto: sobre o que se trabalha? Qual é o objeto? Ou seja, qual é a pertinência? Qual ponto de vista deve-se adotar quando se fala da educação física? Qual ponto de vista científico? Então, o que prevaleceu até hoje é a noção de técnica, e, neste âmbito, a educação física e desportiva conheceu muito desenvolvimento, muito progresso. Isso significa que cada vez mais conhecemos as técnicas de desempenho. Conseguimos realizar atividades físicas altamente avançadas, extremamente agudas, entre as quais, as práticas de atletismo, de natação, exploração da natureza, isso foi muito bem feito, mas sempre em termos de técnica. Isso significa que nós bloqueamos muitas coisas, eles foram colocados em prática, mas não apresentava uma base científica. 
Eis aí o grande problema: a educação física procura registrar-se como uma disciplina de formação superior, mas ela não faz o que é preciso para conseguir isso. Para ter sucesso na universidade, verdadeiramente, temos de ter um objeto, deve-se realizar trabalhos científicos para trazer resultados, deve-se verificar esses resultados, deve-se validá-los, eventualmente, deve-se refutá-los, mas temos de provar estar realizando uma atividade científica, como é feito em química, matemática, geografia, psicologia e sociologia, por exemplo. Até o momento, não se faz na educação física.

Nos limitamos, o que já é interessante, mas nos limitamos apenas a ditar técnicas e ao modo de fazer, então, o que é interessante é que ela não se inscreve como uma disciplina científica. A educação física não fez o aprofundamento epistemológico necessário e os especialistas da educação física não estão preparados para isso, ou seja, no ensino da educação física não há formação epistemológica, científica. Aos alunos, apresenta-se psicologia, sociologia e um pouco de técnicas na literatura. Tudo isso são passos interessantes, mas isso não é uma disciplina científica. O problema epistemológico é: há uma disciplina científica responsável pela educação física? Ou seja, que possa explicar a educação física? Veja a posição do problema.

Há uma resposta para esta questão? Todo o trabalho que fazemos é responder a esta pergunta. Nós respondemos sim, existe a possibilidade de reconhecimento no campo científico, apesar do estado de um pouco de abandono da educação física sob este aspecto.

Aeducação física, atualmente está dividida entre dois grandes riscos. O primeiro é a fragmentação no plano das múltiplas técnicas. O segundo é a vassalização, isto é, a submissão às outras disciplinas. Eu não sei como isso acontece no Brasil, mas na França, por exemplo, há o ensino de múltiplas técnicas: natação, atletismo, ginástica em aparelhos, futebol, lançamento de disco, lançamento de martelo, etc. Muitas técnicas, iniciadas de forma fragmentada, múltiplas técnicas. E depois, uma formação teórica que consiste em justapor conhecimentos de diferentes disciplinas. Há disciplinas de psicologia, sociologia, fisioterapia, anatomia, biomecânica, e se pensa que isso é o suficiente para dar uma marca epistemológica à educação física. Veja, na França acontece assim.

E - No Brasil e na Espanha, também.

Pierre Parlebas - Isso não é do ponto de vista científico. Isto é a tecnologia. Então, é bom, somos todos técnicos. Mas devemos diferenciar técnica bruta, como por exemplo, fazer uma saída na barra fixa, lançar o martelo, o que é muito interessante, mas isso, não é ciência, é tecnologia. O problema está por trás desta tecnologia, em torno desta tecnologia. Há conhecimento na visão do homem, na visão da sociedade que possa fundar uma disciplina científica, não a epistemologia? Há um objeto? Eu Ihes disse, nós respondemos, sim, há um objeto, esse objeto é a prática corporal, a ação motriz. A educação física é uma ciência, uma pedagogia da ação motriz. Veja, o aspecto epistemológico é definido pelo reconhecimento de um objeto, a conduta motriz ${ }^{1}$, a ação motriz. Aqui está a minha primeira resposta. Eu posso ir mais longe, mas, me orientarei por suas perguntas.

\footnotetext{
1 Os conceitos de ação motriz e conduta motriz estão explicitados no Léxico de Pierre Parlebas (2001), obra que está referenciada nesse trabalho. Em português, destaca-se o livro publicado por João Francisco Magno Ribas, jogos e esportes: fundamentos e reflexões da Praxiologia Motriz, lançado em 2008 pela editora da UFSM. Neste livro, que foi baseado em estudos do Grupo de Estudos Praxiológicos do Centro de Lleida- Espanha, o autor divide a obra em duas partes: no primeiro, desenvolvem-se os conhecimentos básicos da Teoria da Ação Motriz, forma como também é conhecida a Praxiologia Motriz, e no segundo momento, apresenta algumas pesquisas realizadas em distintos âmbitos da Educação Física, tendo como base o conhecimento praxiológico.
} 
E: A segunda parte da questão é: onde se encontra a praxiologia motriz no campo da educação física em relação aos outros conhecimentos da área (a fisiologia, a psicologia do esporte, a biomecânica ou sociologia do esporte)?

P: Sim, então, é um problema importante, uma questão central. A educação física não é uma ciência, é uma prática, uma prática onde há uma ou várias pessoas que intervêm para influenciar as condutas motrizes de outras pessoas, dos estudantes de escolas e de universidades. Há, portanto, na educação física, uma intervenção pedagógica, uma ação junto a esses estudantes. Este não é o caso da praxiologia motriz.

A praxiologia é uma ciência. Como ciência, não é normativa. Uma ciência examina as coisas, diz o que acontece, mas ela não tem valor, não é preciso fazer isso, fazer aquilo. A ciência é neutra. Quer dizer que se pode, muito bem, com a física, desenvolver engenhos cirúrgicos que vão salvar vidas humanas graças aos instrumentos físicos, aos materiais, aos aparelhos que vão salvar vidas humanas. Mas com a física, também se pode facilitar a guerra, pode-se facilitar a criação de inventos para destruição. A ciência permite tanto promover a pacificação das massas, a saúde, quanto a guerra. A ciência não tem valor, ela é neutra, ela descreve, ela observa, ela tira conclusões, ela eventualmente emite teoremas matemáticos ou leis, como na física, regularidades. Eu não tenho leis em sociologia ou em psicologia, temos regularidades. Falar de leis em sociologia ou em psicologia é, sem dúvida, excessivo, mas constatamos regularidades no ângulo da probabilidade. Mas isso é a ciência, é a praxiologia motriz, uma ciência que tem por objeto a ação motriz. Mas a educação física tem objetivos, tem finalidades, ela é, como se costuma dizer, normativa, ela quer desenvolver certas normas, é prescritiva, vai depender das propostas políticas.

Em alguns regimes políticos, procurar-se-á desenvolver ações que permitam criar bons operários, bons manutencionistas, bons escravos. Em outros, vai-se querer favorecer o treinamento de bons soldados, na França ou fora dela. Vai-se querer fabricar, com a ajuda da educação física, guerreiros, pessoas capazes de superar os outros. Pode-se procurar desenvolver a saúde, o bem-estar, pode-se procurar desenvolver bons cidadãos, isso vai depender dos países.

Olhe o que está acontecendo em alguns países, queremos formar guerreiros ou revolucionários, ou contrarrevolucionários. Bom, isso é a educação física, isso significa que não há educação física. A educação física dependerá das normas que se deseja aplicar no contexto de uma educação cidadã, política, etc. A grande diferença é que a praxiologia motriz não pretende favorecer tal ou tal finalidade.

A praxiologia motriz estuda tudo o que acontece, tudo o que se faz relacionado, certamente, à ação motriz. O que podemos fazer, o que se desenvolve tanto em um jogo de futebol quanto em um comando do exército que visa libertar reféns? Há, neste último caso, uma praxiologia. $O$ ataque vai se organizar do ponto de vista físico para que tal pessoa salte de paraquedas. Tudo isso é a praxiologia motriz, é a ciência que vai se apoiar em dados de dinâmicas relacionais, mas não é a praxiologia motriz que ataca, que necessita liberar os prisioneiros. Isso é de domínio político. No entanto, a educação física, como eu disse, basta olhar para as obras que se tem na biblioteca, em tal momento se procurou desenvolver tal aspecto da pessoa, queríamos desenvolver a saúde com a ginástica sueca, queríamos desenvolver bons 
soldados, por exemplo, o método de Hébert na França é desenvolvido nas forças armadas. Hébert, você sabe algo sobre Hébert?

E: Sim, criador do método natural.

P: É de Georges Hébert. Bem, Georges Hébert era um tenente, um oficial naval, que desenvolveu o método natural, que tem grande importância na França há meio século. É um método natural que se tornou um método oficial. Ele nasceu no exército, e formavam-se bons soldados, bons infantes da marinha, com a educação física. Veja, a educação física era dependente das normas. Quando a França quis retalhar a Alemanha após a guerra de 1970, foram formados batalhões escolares, e os batalhões escolares eram uma preparação de crianças em idade escolar para se tornarem soldados. Assim, a minha resposta, meu primeiro ponto é de dizer que a praxiologia motriz é uma ciência que não tem nenhum objetivo particular, que não tem nenhuma finalidade educativa, que não é normativa, assim como a física, etc. Enquanto a educação física é uma pedagogia das condutas motrizes, não é uma ciência, procura exercer uma influência.

Esse é o primeiro ponto, isso é capital, é preciso entender bem isso. Então, qual a relação entre educação física e praxiologia motriz? Assim, toda educação física procura exercer uma influência. Mas, para exercer uma influência na conduta motriz, é preciso conhecer as condutas motrizes, por exemplo, conhecer o futebol para tentar desenvolver projetos educativos, lançamento de disco ou a natação.

Em outras palavras, a praxiologia motriz torna-se o suporte fundamental para a educação física que vai, com as normas e objetivos que ela quer desenvolver, se apoiar no conhecimento da ação motriz, da sociomotricidade. Vamos colocar os conhecimentos praxiológicos a serviço das finalidades educativas. Por exemplo, se eu quiser ensinar voleibol. É interessante tratar o voleibol? Poder-se-ia dizer: "-Mas, por quê o voleibol?" A resposta é que o voleibol mobiliza as condutas motrizes do indivíduo de uma forma original com a dinâmica de grupo, tem-se o sentimento de uma equipe, opõe-se a uma outra equipe, existem problemas nas interações, há problemas de antecipação, problemas de cooperação mútua, etc. O corpo é mobilizado numa ação coletiva, tudo isso é, de fato, interessante, numa perspectiva educativa. Como controlar, sem atividade corporal, a manipulação de uma bola, na direção de uma equipe contra a outra equipe?

Tudo isso faz parte do desenvolvimento da motricidade do indivíduo de uma maneira interessante e original. Mas, ao mesmo tempo, há o basquetebol, é preciso fazer escolhas. O voleibol retém, de fato, a perspectiva de uma educação física com base na praxiologia motriz, porque é a praxiologia motriz que irá explicar o que acontece no voleibol. Ocorre que esta é uma ação sociomotriz, o que você fez na prática pedagógica, há problemas de interação, problemas de recepção, antecipação, tomada de decisões. É a praxiologia que explica tudo isso. Nós nos fundamentamos na educação física para promover o desenvolvimento dos praticantes.

E: Pensando na formação de professores de educação física e esporte e na formação das disciplinas, como você situaria a praxiologia motriz no currículo?

P: Para mim, o que é óbvio é que a praxilogia motriz é a coluna vertebral da formação, a base. Mas uma formação em praxilogia motriz, é isso, é o eixo, e este eixo vai ser esclarecido, é claro, por outras disciplinas. Fui Diretor da Faculdade de Sociologia, de modo que nosso eixo era a sociologia, mas, lado a lado, estudávamos 
com uma sensibilização, digamos, pré-formação, em psicologia, em ciência da computação, biologia, medicina. Mas o eixo era a sociologia. Da mesma maneira, em etnologia, formavam-se também etnólogos, o eixo era a etnologia, mas paralelamente havia uma formação em sociologia, em psicologia, em história, todas relevantes. Mas o eixo era a sociologia. Nosso eixo, é claro, é a praxiologia motriz, é esse o eixo. 0 resto, na minha opinião, são especulações, não funciona.

A verdade é que aqueles que ensinam sociologia que são professores de educação física, mas não são sociólogos, eles ainda ensinam sociologia, mas não são sociólogos, eles ensinam biologia, mas não são biólogos. Eles repetem aulas que não correspondem a uma competência certa, não são professores de biologia, eles não são professores de psicologia, eles têm formação, mas é só isso. Há coisas que não se encaixam aqui. $\mathrm{Na}$ universidade, eles devem conhecer bem suas disciplinas. Se você não é um sociólogo, a priori, se você não conhece bem a sociologia, não é o nosso trabalho, a sociologia, a etnologia, a biologia, não é o trabalho do professor de educação física. Sua competência é a praxiologia motriz, é o conhecimento das práticas motrizes, esse é o nosso trabalho. E que não é muito bem feito, porque hoje, por exemplo, vê-se um professor de esqui que não conhece nada de golfe, que não conhece nada de handebol, ele não tem grande conhecimento de conduta motriz.

Portanto, nós, em nossa formação, precisamos de um conhecimento profundo da praxiologia motriz, com todas essas subutilidades, mas ao lado, claro, da biologia, da psicologia, da matemática, o que é significativo, visto que na biologia nem tudo nos interessa no mesmo nível. Há pontos, eu creio, que em biologia, em neurologia, são muito importantes, porque a neurologia é o que vai guiar os problemas de motricidade, de aprendizagem, de prática corporal, então aí, é interessante aprofundar um pouco o fenômeno da radiologia (radiografia), da neurologia.

Mesmo na história pode ser interessante ter alguma perspectiva que mostre a evolução da percepção do corpo, a violência. Isso é relevante, mas, basicamente, a praxiologia motriz irá estudar não a história da agressividade, por exemplo, mas o fenômeno agressivo e ver como, na história, eles vão evoluir. Mas o seu objetivo não é a história da agressividade, o fenômeno da agressividade, com as suas múltiplas influências em determinadas culturas, etc. Por exemplo, o problema que hoje é importante é a diversidade de gêneros. A questão da diversidade de gêneros não é o problema fundamental da praxiologia, mas é muito importante porque temos alunos de escolas.

Eu dirigi uma colônia de férias que era mista, meninos e meninas. Não é simples. Eu estava partindo para acampar, vários dias, com um grupo de oito meninos e oito meninas, adolescentes. Bem, obviamente, haviam problemas psicológicos, sociológicos. O que me interessava não era apenas fazer um estudo de gênero, um estudo psicológico do homem e da mulher. Era como permitir um desenvolvimento da personalidade de meninos e meninas, em um quadro de prática motriz, considerando o conhecimento sociológico e psicológico com relação a homens e mulheres.

Veja bem, o problema é que o professor de educação física é confrontado constantemente com situações de dinâmicas de grupo. A dinâmica de grupo é a psicossociologia, então, é preciso conhecê-la. Esta é uma das minhas especialidades, a psicologia social e eu realizei intervenção social nos grupos de conversas, o que 
não é motricidade. Intervinha-se junto aos alunos de faculdades, era um ponto de vista cognitivo, eram debates, etc.

Não é tudo o que acontece na educação física. Dinâmica de grupo em educação física é uma dinâmica interativa, intercorporal, bem diferente. Você tem que se mover, você tem que ocupar o espaço, você tem que lutar, tem corpo a corpo ou distanciamento, uso de uma raquete ou uma bola. De fato, porque esse é o nosso trabalho, é como a relação interpessoal pode permitir pelo intermédio das práticas corporais o desenvolvimento da relação com o outro, de viver juntos. Trabalha-se tudo. O eixo, a praxiologia motriz coloca informações em nexo.

Portanto, há um problema particular em nossa época que até então não havia o conhecimento da praxiologia motriz. Quando eu era estudante, no INSEP, depareime com a justaposição de aulas. Como jovem professor, percebi que isso não ia bem. Então, adquiri formação em psicologia e matemática, e nós, a minha geração de professores e vocês também, somos destinados a aprofundar nossos conhecimentos em outras disciplinas para criar a praxiologia motriz. Inicialmente, é necessário que muitos de nós "domine", tente ver claramente, para fundar a praxiologia motriz e isso exige de nossos pares um grande trabalho de aprofundamento de conhecimento. Não em todos os lugares, mas em sociologia, matemática, etc, então é preciso um trabalho de grupo. Isso é para agora, mas mais tarde, isso não vai acontecer novamente. Mais tarde, talvez em dez anos, vinte anos, tudo isso vai ser adquirido e não se terá mais necessidade de justificar a praxiologia motriz. Ela conseguirá se afirmar sozinha, como a sociologia, como a psicologia.

Quando comecei meus estudos de psicologia na Sorbone eu era um jovem estudante. A psicologia não era reconhecida, ela quase não existia, e foi realizada na Sorbonne, a primeira graduação em psicologia. Os médicos diziam que a psicologia não existia, que eram eles, os médicos, que conheciam a alma humana. Precisou anos de batalha para que os psicólogos tivessem sucesso. Hoje, os psicólogos estão por toda parte. Há um acidente, ataques terroristas, lá estão os psicólogos. É preciso Ihes dizer que há 30 ou 40 anos, eu tinha colegas de filosofia que queriam o diploma de psicologia, e eles não iam à aula. Isso foi possível, porque diziam que a psicologia era fácil e não participavam das aulas. Isso foi possível após a guerra de 45 contra os alemães. Era possível, mas após alguns anos, a psicologia se impôs e os filósofos não puderam mais fazer as provas.

Pouco a pouco, a psicologia impôs seu objeto, que não era conhecido desde o início, seu objeto, que era o comportamento, impôs seus métodos e suas teorias, o que fez com que agora seja absolutamente impossível ter diploma de psicologia sem ir às aulas. E com a sociologia ocorreu o mesmo. A psicologia continuou se desenvolvendo. A psicologia se impôs nos anos 40,48, 49, e o primeiro diploma em psicologia é recente, é de 56,57 . Na época, a psicologia não era reconhecida.

Hoje, quem pode negar a importância da psicologia para as pessoas? Bem, nós temos essa situação aqui na França. Estamos num momento em que a praxiologia motriz não é bem conhecida, discutida, é combatida, porque incomoda as pessoas que não são competentes neste domínio, que não querem trabalhar, que querem ficar no seu canto, tranquilas. Então, perturbamos essas pessoas e elas se opõem à praxiologia motriz, tal como as que se opuseram à psicologia, à sociologia. Mas elas serão inundadas em breve por pessoas como vocês, que querem avançar. 
Estamos em uma fase de discussão, combate, onde você tem que propor uma nova perspectiva, então, é preciso propor através de afirmações, mas por trabalho de campo, por livros, é muito importante através de memórias como esta.

Vamos desenvolver a praxiologia pelo seu trabalho “...” aqui, na Espanha, Itália, etc. Eles estão lutando porque nós temos especialmente contra nós - e é isso que é paradoxal - especialistas em educação física. Na França, foram os matemáticos que permitiram desenvolver-me, que me sustentaram, paradoxal, e não os professores de educação física, os matemáticos, os psicólogos, sociólogos, eles que me apoiaram, que me ajudaram, que estavam na minha defesa de tese. O presidente da banca da minha defesa de tese era um matemático. Eu não queria professores de educação física, eu disse que não queria que os professores de educação física, porque eles não eram competentes, eles não estavam contentes. E então, em minha tese, eu dizia, mas, na verdade, o problema não é fazer a matemática, não é fazer sociologia, psicologia, mas é usar essas disciplinas para fundar uma nova disciplina. Por isso, foi mesmo publicado na revista de psicologia, e os professores que estavam na banca eram os professores de indiscutível ponto de vista sociológico, Raymond Boudon e Claude Flament, humanas, filosofia e psicologia social, todos os grandes nomes das disciplinas que estavam lá ${ }^{2}$, e que aprovaram integralmente com as maiores menções.

Eu Ihes dizia: "O que eu faço não é o que você faz, mas eu uso o que você faz para melhor desenvolver a praxiologia motriz". Portanto, antes de ser aprovado, antes de defender, eu pensei, "ou vai ou racha", era um ou o outro, ou eles me diriam que era ruim, ou pelo contrário, todos aprovariam, e foi o que aconteceu. Independentemente da minha pessoa, o que é importante não sou eu, são as ideias.

A praxiologia motriz irá se desenvolver por colegas, por vocês, que vão retomar, que vão encontrar novos desdobramentos, ir mais longe do que nós. É preciso ir mais longe, o que fiz, para desenvolver? Mas, então, na minha opinião, é preciso apoiarse, parece-me, na praxiologia motriz. Não tenho mais nada, eu desenvolvi isso em 60 , há meio século, e nada se opôs seriamente. E não surgiu nada que ofereça outra proposta? Vocês conhecem outras propostas similares? Simplesmente o que dizem na França é: "Vão fazer psico, sociologia"? Eu respondo a eles: "Eu sou um sociólogo, você, você não é. Então, quando você faz a sociologia, o que você faz?".

Enquanto aqueles, entre meus colegas, que vão fazer praxiologia, lá é o seu domínio. Você, no voleibol, quando você vai analisar o voleibol, vamos ouvi-lo, porque você sabe, e você o coloca em um quadro da ação motriz. Nesta situação, você é o chefe. O sociólogo vai ouvi-lo, não é você que tem que seguir o sociólogo, é o sociólogo que virá para ouvi-lo, porque é você que conhece o voleibol. Todas as outras áreas terão que ouví-lo, como a, psicologia, biologia, etc. Há ramos da biologia, é claro, a manchete não é qualquer coisa, o ataque, etc, é preciso saltar. Há também aspectos psicológicos, ele deve querer defender, existem problemas de dinâmica de grupo, temos que nos comunicar de acordo, mas tudo está centrado na ação motriz, e você é o chefe da ação motriz. Entenderam o que eu quero dizer?

E: Em linhas gerais, consideramos como trabalho pedagógico todo o tipo de trabalho cujas bases estão de alguma forma relacionadas com a pedagogia, com

2 A banca de doutoramento em Letras e Ciências Humanas de Pierre Parlebas foi formada pelos seguintes membros: Marc BARBUT (Matemática e Ciências Humanas) - Presidente da Banca; Claude BREMOND (Semiologia), Jacques LAUTMAN (Sociologia); Raymond BOUDON (Sociologia); Jacques ULMAN (Ciência da Educação); Claude FLAMENT (Psico-sociologia). 
avaliações, portanto, métodos, técnicas e intencionalmente planejadas para atingir os objetivos relacionados com a produção de conhecimentos. Trata-se da produção de conhecimento, crenças e contribuições teórico-metodológicas selecionadas pelos sujeitos, que se desenvolve nos contextos sociais e políticos e que contribuem direta ou indiretamente com eles.

Pergunta: qual é o papel da praxiologia motriz na organização do trabalho pedagógico do professor de educação física?

P: É preciso substituir isso por um quadro epistemológico onde o único objeto é a ação motriz. Mas agora, graças ao trabalho de sociólogos, biólogos, psicólogos, sabemos que a ação motriz pode dar lugar a manifestações de toda a personalidade.

A ação motriz não é apenas chutar uma bola, não é apenas fazer gestos, é expressar sentimentos, emoções, representações, ou seja, é toda a personalidade que pode ser envolvida na ação motriz. Isso mostra que a educação física pode se inscrever no campo da educação em geral, porque se trata de jogar em todas as facetas da personalidade. Âmbitos cognitivos, pode-se intervir na inteligência motriz através de atividades motrizes, a avaliação da distância, velocidade, cálculo. Isso é a inteligência motriz, a afetividade, a emoção, os sentimentos, as relações. Tudo isso está envolvido na dimensão emocional que influencia muito na personalidade. Há também o aspecto de interação. Eu tenho companheiros, adversários, então, uma dimensão social e interacional.

Finalmente, atua-se no âmbito das normas sociais. Por exemplo, se eu jogar rugby, eu sigo as regras de rugby, não fui eu que as inventei. É a sociedade que impõe regras e a instituição que organiza tudo isso. Eu resumo isso: quando o professor de educação física intervém de um ponto de vista pedagógico na ação motriz, ele pode jogar em todas as dimensões da personalidade, que é capital, porque é aí que nos entramos no campo educativo. E se quisermos convencer os pais, os outros professores de outras disciplinas, políticos, isto é o que devemos mostrar.

Você tem que mostrar que o futebol não é apenas chutar uma bola, é ter interações. Isso não é bem entendido na França, é dito um monte de coisas, mas não se vai a fundo. O âmago da questão é que, quando se intervém na ação motriz, na conduta motriz de crianças, adolescentes intervêm-se no conjunto de suas personalidades. Isso significa que o praticante sente emoções, sem interações com os outros, coloca em jogo a sua empatia sociomotriz, há alguma turbulência pessoal que promove o desenvolvimento de certas habilidades, que favorece um certo viver junto.

Finalmente, a atividade motriz não é o arranjo de gestos e técnicas, é um envolvimento de toda uma personalidade, isso é realmente o ponto crucial. Assim, tudo ocorre a partir disso. A partir do momento em que você percebe que mobilizando a ação motriz, promovendo a sua prática, o seu desenvolvimento, joga-se com toda a personalidade, então, talvez, seremos capazes de intervir na sua inteligência, sua capacidade de pensar, seu destino provável, etc. Mas, também é possível conter a agressividade, sua relação com os outros, o prazer que ele tem com os outros. Esse aspecto também poderá ser contemplado no domínio da educação física. É a mesma coisa que aprendermos bem a arte de salto com vara, que é muito importante, mas eu não sei se aprendi como vocês. Eu aprendi salto com vara em Paris. Eu acho que nunca vou usar isso na minha vida, eu passei horas no arremesso de peso, como 
aluno e como professor, eu carreguei uma pedra de sete quilos no meu bolso. Ou seja, para que me serviu? Passei horas no arremesso de peso, aparentemente, não serve para nada.

Então para que serve a educação física? A ideia é que por trás das práticas que ensinamos, existem metas mais importantes do que a técnica em si, há a influência da lógica interna, da prática na personalidade do sujeito. Isso significa que através do uso do voleibol, natação, judô, esgrima, vamos tentar intervir nas características pessoais para promover, por exemplo, o respeito pelos outros, a relação com o outro, o desejo de ter sucesso. Vamos tentar intervir profundamente nas condutas do sujeito, servindo-se da conduta motriz, tendo um objetivo que vai além da técnica esportiva, então, esse é o ponto capital. O ponto crucial é isso, como parte da primeira questão que você acabou de me perguntar sobre o objeto da educação física, mas, em seguida, respondi que a praxiologia motriz estudava todas as situações motrizes, permitindo ver claramente, através da lógica interna, isto é, as características de cada situação. Lógica interna é a relação com os outros, a relação com o espaço, que acabo de mencionar. Será que é somente isso? De um lado há a praxiologia motriz, do outro lado, a educação física.

A educação física, como tal, é uma intervenção pedagógica, e esta volta para o campo da praxiologia motriz, isso significa que a praxiologia motriz é também o estudo da aprendizagem. Como podem as condutas motrizes evoluirem no sentido de possibilitar a programação de conteúdos? E tudo isso pode ser estudado pela praxiologia motriz, é o que fazemos no campo, é o problema de aprendizagem. O que é o aprendizado do salto em distância, do nado peito, nado borboleta, nado livre? Como vamos usar o conhecimento que temos da praxiologia motriz para controlar com êxito o meio aquático? É tudo parte da praxiologia motriz, que estuda a ação motriz em seu desenvolvimento, em seu processo. Então, veja, a praxiologia motriz também estuda as situações da educação física escolar. Os colegas não conseguem dominar tudo isso, porque não têm uma formação científica e não são habituados a dominar os conceitos, as variáveis dependentes e independentes, como propus.

Quando me formei professor de educação física, eu era como meus colegas. Éramos bons técnicos, mas não tínhamos formação científica, não éramos capazes de realmente debater este problema. Então, os colegas não estão em questão, é a sua formação que está em questão, que não os formou para isso. É preciso preparálos, é preciso preparar nossos alunos da universidade para isso.

\section{REFERENNCIAS}

CAPARROZ, Francisco Eduardo; BRACHT, Valter. O tempo e o lugar de uma didática da educação física. Revista Brasileira de Ciências do Esporte, v. 28, n. 2, jul. 2008. Disponível em: http://revista.cbce.org.br/index.php/RBCE/article/view/53. Acesso em: 25 out. 2018.

CARLAN, Paulo; DOMINGUES, Soraya Corrêa; KUNZ, Elenor. Didática da educação física brasileira: uma compreensão da produção científica. Pensar a Prática, v. 12, n. 3, nov. 2009. Disponível em: https://www.revistas.ufg.br/fef/article/view/7674. Acesso em: 25 out. 2018. 
PARLEBAS, Pierre. Juegos, deporte y sociedad: Léxico de Praxiología Motriz. Barcelona: Paidotribo, 2001.

RIBAS, João Francisco Magno. Jogos e Esportes: Fundamentos e Reflexões da Praxiologia Motriz. Santa Maria, RS: UFSM, 2008. p.153.

SARAVÍ, Jorge Ricardo. A praxiologia motriz: presente, passado e futuro. Entrevista com Pierre Parlebas. Movimento, p. 11-35, abr. 2012. Disponível em: http://www.seer.ufrgs.br/ index.php/Movimento/article/view/27065. Acesso em: 25 out. 2018.

\section{Apoio:}

A tradução da entrevista foi realizada pela professora Cristina Machado Severo e contou com o apoio da Fundação de Amparo à Pesquisa do Estado do Rio Grande do Sul (FAPERGS). 